\title{
Mass Gatherings and Hazard Control: Agenda for Education and Implementation
}

\author{
Francis T. Pleban
}

\section{Contents}

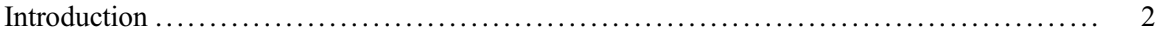

Control Hierarchy for Common Mass Gathering Hazards $\ldots \ldots \ldots \ldots \ldots \ldots \ldots \ldots \ldots \ldots \ldots \ldots \ldots$

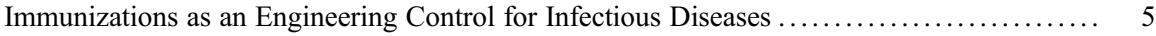

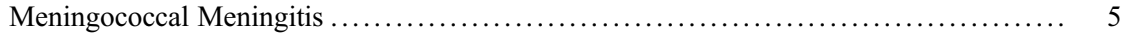

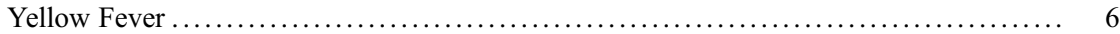

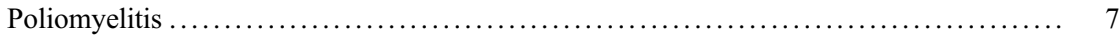

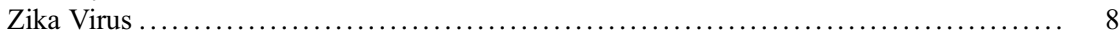

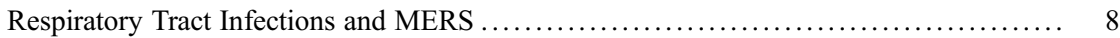

Personal Hygiene as an Administrative Control for Infectious Diseases . . . . . . . . . . . . . . . 9

Personal Protective Equipment as a Control for Respiratory and Infectious Diseases ....... 10

Surgical Masks ....................................................... 11

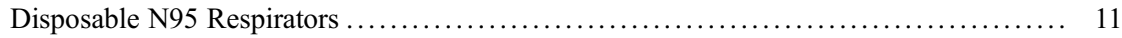

Public Use N95 Respirators ............................................ 12

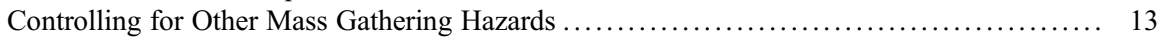

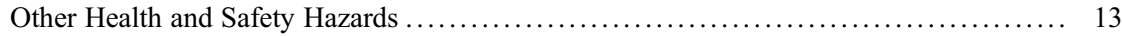

Personal Responsibility in Abiding by General Posted Health Guidelines as Engineering,

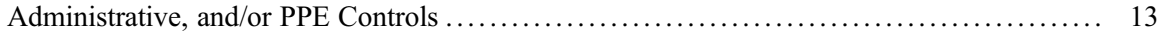

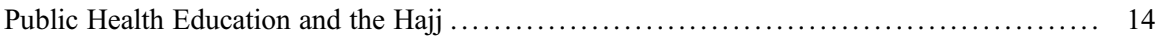

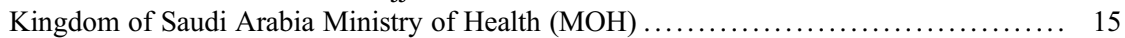

During Hajj MOH Health Education Guidelines ............................... 16

Pilgrims with Chronic Disease Conditions MOH Health Education Guidelines .......... 17

Women and Children Pilgrims MOH Health Education Guidelines ................... 18

After Hajj MOH Health Education Guidelines ................................ 19

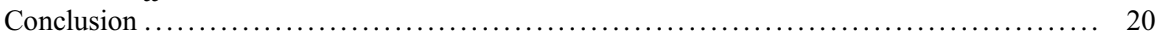

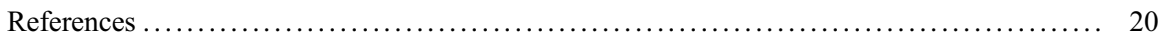

\footnotetext{
F. T. Pleban $(\bowtie)$

College of Health Sciences, Department of Public Health, Health Administration and Health Sciences, Tennessee State University, Nashville, Tennessee, USA

e-mail: fpleban@tnstate.edu
} 


\section{Abstract}

The Hajj is an annual pilgrimage to Mecca, Saudi Arabia, attended by approximately two million Muslims. To promote a healthy pilgrimage, travelers should proactively look to recognize, prevent, and control those health or environmental stressors, arising in or from the Hajj. A hierarchy of controls to hazards has been employed as a means of determining how to implement meaningful control solutions. The Centers of Disease Control (CDC) and the National Institute for Occupational Safety and Health (NIOSH) lists ordered hazard control measures as: (1) Elimination, (2) Substitution, (3) Engineering Controls, (4) Administrative Controls, and (5) Personal Protective Equipment (PPE). Elimination, substitution, engineering, and administrative controls are favored over the use of PPE; however, specifically in the case of mass gatherings, those controls are not always feasible. Administrative controls, such as behavioral personal hygiene interventions, which include hand hygiene, proper cough etiquette, social distancing, and contact avoidance can be effective at mitigating respiratory illness and other infectious diseases (Brunette and Centers for Disease Control and Prevention [CDC], CDC health information for international travel 2016: the yellow book. Oxford University Press, New York, 2016). Immunizations, as an engineering control, are designed to remove the hazard at the source, before it comes in contact with an individual (American Chemical Society [ACS], Control measures. Retrieved from https://www.acs.org/content/acs/en/about/governance/com mittees/chemicalsafety/hazard-assessment/fundamentals/control-measures.html, 2015). The initial cost of immunizations can be higher than the cost of personal protective equipment; however, over time, they can produce a cost saving in terms of reduced further medical care. For personal protective equipment to be effective, PPE should be properly worn and maintained in a clean and reliable fashion before, during, and after use (Occupational Safety and Health Administration [OSHA] 2016). The Kingdom of Saudi Arabia Ministry of Health established health guidelines, disseminated electronically through the $\mathrm{MOH}$ portal, specific to the health education of Hajj pilgrims addressing: (1) During Hajj, (2) Chronic Diseases, (3) Woman and Child, and (4) After Hajj (Saudi Ministry of Health, Media center. Retrieved from https://www.moh.gov.sa/en/ Pages/Default.aspx, 2018a).

\section{Keywords}

Environmental health and safety $\cdot$ Hazard control $\cdot$ Mass gatherings

\section{Introduction}

The Hajj, part of the Islamic faith, is an annual pilgrimage to Mecca, Saudi Arabia. For Muslims, Mecca is the most holy city and the site of the largest mass gathering in the world (Brunette and Centers for Disease Control and Prevention [CDC] 2016). Every adult Muslim, being physically and financially capable, is obligated to carry 
out this religious pilgrimage at least once in his or her lifetime (Brunette and Centers for Disease Control and Prevention [CDC] 2016). The Hajj takes place during the last month, or Dhu al-Hijja, of the Islamic lunar year. In all, approximately two million Muslims from nearly 183 countries attend the Hajj each year. In helping to promote a successful and healthy pilgrimage, individuals should proactively look to recognize, prevent, and control those health or environmental stressors, arising in or from the Hajj, which may cause illness, significant discomfort, or diminished health and well-being.

Historically during Hajj, pilgrims have had an increased risk of exposure to, and subsequently experienced, a number of illnesses and injuries, including: incidence of new respiratory disease and exacerbation of existing respiratory conditions, increased cardiovascular disease and disability, food-borne illnesses; diarrheal diseases; well as psychosocial stressors aggravating behavioral, mood, and sleep disorders (Masood et al. 2007; Meysamie et al. 2006). During the Hajj, respiratory tract infections are common, with pneumonia cited as the most common respiratory tract infection leading to hospitalization (Brunette and Centers for Disease Control and Prevention [CDC] 2016). As well, crowded conditions created during the Hajj increase the risk of tuberculosis and influenza transmission (Brunette and Centers for Disease Control and Prevention [CDC] 2016). Chronic health conditions, specifically cardiovascular conditions, were associated with 46-66\% of pilgrim deaths during the Hajj (Brunette and Centers for Disease Control and Prevention [CDC] 2016). Factors associated with exacerbating illness and injury during the Hajj include changes in sleep and diet; as well as increased physical exertion in classically hot climate conditions (Meysamie et al. 2006).

\section{Control Hierarchy for Common Mass Gathering Hazards}

Traditionally, in occupational and environmental health, a hierarchy of control to hazards has been employed as a means of determining how to implement meaningful control solutions. The Centers of Disease Control (CDC) and the National Institute for Occupational Safety and Health (NIOSH) lists ordered control measures to a specific hazard as: (1) Elimination, (2) Substitution, (3) Engineering Controls, (4) Administrative Controls, and (5) Personal Protective Equipment (PPE). Elimination, substitution, engineering, and administrative control methods are theoretically more effective and protective than PPE (i.e., gloves, safety glasses, earplugs or muffs, face shields, or facemasks and/or respirators) (Centers for Disease Control and Prevention [CDC] 2015). Elimination, substitution, engineering, and administrative controls are favored over the use of PPE; however, especially in the case of mass gatherings, those controls are not always feasible.

Elimination and substitution are typically most effective at reducing hazards, but are sometimes difficult to implement within existing practices or situations. As well, engineering and administrative controls are also preferred, because these methods are designed to remove hazards at the source, before coming in contact with the individual (American Chemical Society [ACS] 2015; Centers for Disease Control and Prevention [CDC] 2015). 
Engineering controls involve making changes to an individual's environment in order to reduce hazards. Engineering controls are favored over all other controls because they make permanent changes that reduce hazard exposure; not relying solely on personal behavior for protection (Occupational Safety and Health Administration [OSHA] 2016; American Chemical Society [ACS] 2015).

Administrative controls modify schedules and tasks in ways that minimize a person's exposure to a particular hazard. Behavioral practices can be employed to reduce the duration, frequency, or intensity of individual or collective exposure to a hazard (Occupational Safety and Health Administration [OSHA] 2009a). Providing resources and promoting personal hygiene are forms of administrative controls. Examples of resources include providing: facial tissues, hand soap, disposable towels, hand sanitizer, disinfectants, and no-touch waste containers (Centers for Disease Control and Prevention [CDC] 2009). Examples of behavioral health promotion include providing: up-to-date education and training on hazard risk factors, protective personal hygiene education and instruction on proper hygiene behaviors (i.e., cough etiquette, avoiding touching eyes, nose and mouth, and social distancing) (Occupational Safety and Health Administration [OSHA] 2009a; Occupational Safety and Health Administration [OSHA] 2016).

Public health surveillance and monitoring stations may also act as administrative controls. Both permanent and Hajj seasonal event health facilities have been established. Permanent and Hajj seasonal event hospitals, health centers, cooling/rest stations, and medical transportation have been put in place to address routine and emergency cases, as well as to monitor travelers, during the pilgrimage (Eltahir 2000).

Personal protective equipment (PPE) is applied protective devices with the intention of keeping individuals safe in the presence of a hazard (Occupational Safety and Health Administration [OSHA] 2016). Examples of PPE include facemasks (e.g., N95 respirators), face shields, goggles, and disposable gloves. Personal protective equipment, although initially more cost efficient to implement, requires a concerted individual effort for proper use and protection. If appropriately used and maintained, PPE can help prevent some exposures. However, PPE should not take the place of other prevention interventions, such as engineering controls or administrative public health promotion interventions (i.e., cough etiquette and hand hygiene). It is important to note that for personal protective equipment to be effective, PPE should be maintained in a clean and reliable fashion before, during, and after use (Occupational Safety and Health Administration [OSHA] 2016).

Important PPE considerations include (1) proper selection based on the specific hazard; (2) proper size and fitting (e.g., respirators and gloves); (3) conscientious and proper wearing; (4) regular servicing and replacing of PPE following manufacturer's specifications; (5) proper removal and disposal to avoid possible contamination of self, others, or the environment; and (6) if it is a reusable device, to ensure it is properly removed, cleaned, disinfected, and stored following the manufacturer's specifications (Occupational Safety and Health Administration [OSHA] 2009a). 


\section{Immunizations as an Engineering Control for Infectious Diseases}

To help prevent and control for a variety of viral or bacterial infections, each individual pilgrim should maintain a current immunization schedule during the time leading up to the Hajj. Before travel, immunization can reduce a person's risk of contracting some diseases. In the United States, vaccines are categorized as either routine or travel. Routine vaccines typically include tetanus, diphtheria, flu, varicella, measles, mumps and rubella, polio, hepatitis B, meningococcal, and pneumococcal. Travel vaccines are comprised of hepatitis A, typhoid, rabies, Japanese encephalitis, and yellow fever (Vanderbilt Health 2017).

The CDC (Brunette and Centers for Disease Control and Prevention [CDC] 2016) recommends that all Hajj pilgrims remain up-to-date with routine immunizations, particularly for meningococcal meningitis. For U.S. pilgrims, travel vaccines for hepatitis $\mathrm{A}$ and $\mathrm{B}$ and typhoid are recommended. The required polio vaccine does not include adult Hajj pilgrims from the United States. However, it is best that individuals confirm full vaccination against polio before travel (Brunette and Centers for Disease Control and Prevention [CDC] 2016).

The Saudi Arabia Ministry of Health requires visitors from any country arriving for the Hajj pilgrimage to produce documentation of vaccination against meningococcal meningitis infection, protecting against quadrivalent serogroups A, C, W, and Y (ACWY). Also, the Saudi Arabia Ministry of Health has additional vaccination requirements for Hajj pilgrims entering from countries outside of the United Kingdom (UK) which include yellow fever and poliomyelitis (Saudi Ministry of Health 2016).

\section{Meningococcal Meningitis}

Crowded conditions and the high carrier-rate risk of meningococcal disease among pilgrims, have led to historical outbreaks during Hajj. After the 2000 and 2001 meningococcal disease outbreaks, the Saudi Ministry of Health began requiring all pilgrims to show documentation of the quadrivalent (ACWY) meningococcal vaccine (Brunette and Centers for Disease Control and Prevention [CDC] 2016). All adults and children above 2 years of age must receive at least a single dose of tetravalent (ACYW135) vaccine and provide valid administered vaccination documentation of not more than 3 years and not less than 10 days prior to arrival in Saudi Arabia. Both meningococcal polysaccharide and conjugate vaccines are considered valid options. Polysaccharide meningococcal vaccination delivers protection of at least 3 years with conjugate meningococcal vaccination providing at least 8 years of protection.

Pilgrims arriving from counties identified in the "African Meningitis Belt" have been shown to have the highest Neisseria meningitidis incidence rates (Table 1) (The Council of British Hajjis [CBHUK] 2010; Brunette and Centers for Disease Control and Prevention [CDC] 2016). Pilgrims visiting or residing in this region or countries where meningococcal disease is hyperendemic or epidemic, should 
Table 1 Countries in the "African Meningitis Belt" (Ministry of Health - Kingdom of Saudi 2017a)

\begin{tabular}{l}
\hline Benin \\
\hline Burkina Faso \\
\hline Cameroon \\
\hline Chad \\
\hline Central African Republic \\
\hline Eote d'Ivoire \\
\hline Ethiopia \\
\hline Gambia \\
\hline Guinea \\
\hline Guinea-Bissau \\
\hline Mali \\
\hline Niger \\
\hline Nigeria \\
\hline Senegal \\
\hline Sudan \\
\hline South Sudan \\
\hline
\end{tabular}

receive vaccination with a quadrivalent meningococcal vaccine before the date of travel (Brunette and Centers for Disease Control and Prevention [CDC] 2016). For pilgrims residing in these regions, either the MenACWY vaccine (people aged 2 months through 55 years and meningococcal vaccine non-naïve people aged $\geq 56$ years) or MPSV4 (meningococcal vaccine-naïve people aged $\geq 56$ years) are recommended before travel (Brunette and Centers for Disease Control and Prevention [CDC] 2016). In addition to the stated meningococcal vaccination requirements, the additional application antibiotic prophylaxis regimen with ciprofloxacin is recommended for administration to adults (excluding pregnant women) and children over 12 years of age at the port of entry into Saudi Arabia (World Health Organization [WHO] 2016).

\section{Yellow Fever}

Beginning in 2005, pilgrims arriving from countries or regions identified at risk of yellow fever transmission must also provide valid documentation of yellow fever vaccination (World Health Organization [WHO] 2016). For valid yellow fever documentation, pilgrims must show that vaccination was administered at least 10 days before arrival in Saudi Arabia (Brunette and Centers for Disease Control and Prevention [CDC] 2016). Table 2 lists countries and/or regions identified at risk for yellow fever transmission (World Health Organization [WHO] 2016). 
Table 2 Counties and/or regions at risk for yellow fever

\begin{tabular}{l|l}
\hline Africa & Americas \\
\hline Angola & Argentina \\
\hline Benin & Bolivia \\
\hline Burkina Faso & Brazil \\
\hline Burundi & Colombia \\
\hline Cameroon & Ecuador \\
\hline Chad & French Guiana \\
\hline Congo & Guyana \\
\hline Côte d'Ivoire & Panama \\
\hline Equatorial Guinea & Paraguay \\
\hline Ethiopia & Peru \\
\hline Gabon & Suriname \\
\hline Gambia & Trinidad and Tobago \\
\hline Ghana & Venezuela \\
\hline Guinea & \\
\hline Guinea-Bissau & \\
\hline Kenya & \\
\hline Liberia & \\
\hline Mali & \\
\hline Mauritania & \\
\hline Niger & \\
\hline Nigeria & \\
\hline Senegal & \\
\hline Sierra Leone & \\
\hline Sudan & \\
\hline South Sudan & \\
\hline Sudan & \\
\hline Togo & \\
\hline Uganda & \\
\hline & \\
\hline & \\
\hline
\end{tabular}

\section{Poliomyelitis}

As of 2017, regardless of age and vaccination status, pilgrims must also show proof of receipt within the previous 12 months (and at least 4 weeks prior to departure) of a dose of oral polio vaccine (OPV), or inactivated poliovirus vaccine (IPV), before entry to Saudi Arabia (World Health Organization [WHO] 2016). Table 3 identifies (as of 2017) countries or regions require proof of vaccination receipt. Pilgrims from listed countries (as of 2017) will also receive 1 dose of OPV on arrival at Saudi Arabia point of entry (World Health Organization [WHO] 2016). 
Table 3 Countries requiring proof of poliomyelitis vaccination

\begin{tabular}{l}
\hline Afghanistan \\
\hline Pakistan \\
\hline Guinea \\
\hline Laos \\
\hline Madagascar \\
\hline Myanmar \\
\hline Nigeria \\
\hline Ukraine \\
\hline Somalia \\
\hline Syria
\end{tabular}

\section{Zika Virus}

As of 2017, the Aedes aegypti mosquito has not been found at either the Hajj or Umra areas; however, the Aedes aegypti mosquito is present in surrounding locales (World Health Organization [WHO] 2016). The Zika virus has not been detected in Saudi Arabia. The Ministry of Health of Saudi Arabia recommends Hajj and Umra travelers to take measures to avoid insect bites during daytime and nighttime hours to reduce the risk of infection of mosquito borne diseases (World Health Organization [WHO] 2016). Insect bite avoidance measures include:

1. The use of insect repellent. Environmental Protection Agency (EPA)-registered insect repellent with one of the following active ingredients (a. DEET; b. Picaridin; c. Oil of lemon eucalyptus (OLE) or para-menthane-diol (PMD); d. IR3535) is recommended (Centers for Disease Control and Prevention [CDC] 2017). Used as directed, EPA-registered insect repellents have been shown to be safe and effective, even for pregnant and breastfeeding women (Centers for Disease Control and Prevention [CDC] 2017).

2. Cover as much of the body as possible. Wear long-sleeved shirts and long pants.

3. Keep mosquitoes out of the living/sleeping environment. If inside, utilize window and door screens. If outside, sleep under mosquito bed netting.

\section{Respiratory Tract Infections and MERS}

Respiratory tract infections are common during Hajj, with pneumonia documented as the most common cause of hospital admission (Shafi et al. 2016). The pneumococcal polysaccharide vaccine is recommended for those pilgrims over 65 years of age, as well as for younger pilgrims with comorbidities (Shafi et al. 2016). As well, the Ministry of Health of Saudi Arabia recommends the administration of the most current seasonal influenza vaccine, including H1N1. 
Crowded conditions created during the Hajj also increase the probability of tuberculosis and Middle East respiratory syndrome (MERS) transmission (Brunette and Centers for Disease Control and Prevention [CDC] 2016). Middle East respiratory syndrome (MERS) was first identified in Saudi Arabia in 2012. Cases of MERS have been identified in and around the Arabian Peninsula, with the exportation of cases to other countries, including the United States.

MERS is caused by a unique coronavirus, similar to the severe acute respiratory syndrome (SARS) virus responsible for the 2003 global outbreak (Centers for Disease Control and Prevention [CDC] 2012). Severity of illness can range from mild to severe, with fatality in approximately $35 \%$ of the reported cases (Brunette and Centers for Disease Control and Prevention [CDC] 2016). Currently, no vaccine or preventive drug is available for MERS. General personal hygiene precautions against MERS are recommended for pilgrims, such as frequent handwashing; avoid touching eyes, nose, and mouth; and avoiding contact with other sick travelers (Brunette and Centers for Disease Control and Prevention [CDC] 2016).

Engineering controls, such as immunizations, are designed to remove the hazard at the source, before it comes in contact with an individual (American Chemical Society [ACS] 2015). A well-designed immunization schedule can be highly effective in protecting individuals. Initial cost of immunizations can be higher than the cost of personal protective equipment; however, over time, they can produce a cost saving in terms of reduced further medical care.

\section{Personal Hygiene as an Administrative Control for Infectious Diseases}

Standard public health personal hygiene practices can act as a general administrative control for infectious disease. Behavioral interventions as administrative controls such as hand hygiene, proper cough etiquette, social distancing, and contact avoidance can be effective at mitigating respiratory illness and other infectious diseases among Hajj pilgrims (Brunette and Centers for Disease Control and Prevention [CDC] 2016).

The Ministry of Health of Saudi Arabia (Ministry of Health - Kingdom of Saudi Arabia. 2017a) advises all pilgrims to apply recommended personal hygiene procedures, particularly after coughing and sneezing, after using the toilet, before handling and consuming food, and after handling animals: (1) wash hands with soap and water and (2) if soap and water is not readily available, use sanitizers with a form of alcohol, such as ethyl alcohol, as an active ingredient (World Health Organization [WHO] 2016).

Additional personal hygiene recommendations (World Health Organization [WHO] 2016) include:

1. Use of disposable tissues when coughing or sneezing and properly disposing of them afterwards in appropriate waste containers.

2. Avoid hand contact with the eyes, nose, and mouth. 
3. Avoid direct contact with persons who appear ill, exhibiting conditions exhibiting coughing, sneezing, expectorating, vomiting, and/or diarrhea.

4. Avoid sharing of personal belongings.

5. Avoid close contact with animals or eating meat that has not been properly prepared and cooked.

\section{Personal Protective Equipment as a Control for Respiratory and Infectious Diseases}

The use of personal protective equipment (PPE) is a way of controlling hazards by placing a protective barrier between the person and hazard (New York Committee for Occupational Safety and Health n.d.). As noted, personal protective equipment is the least effective method for protecting an individual from hazards and should be utilized after all other effective mechanisms to control the hazard have been exhausted. Caution is advised in utilizing PPE for hazard control because: (1) the hazard itself is not eliminated or changed, (2) improper PPE may be inadequate or fail, (3) PPE is not $100 \%$ effective in controlling a hazard, and (4) some personal protective equipment may be uncomfortable and place additional physical stress on an individual (Centers for Disease Control and Prevention [CDC] 2015). In helping to decrease any potential body burden placed on an individual from PPE use, there is one basic engineering control pilgrims can utilize before travel - immunizations (New York Committee for Occupational Safety and Health n.d.).

The most common PPE devices for respiratory infection control are surgical masks and disposable N95 respirators. There are significant differences between these two types of personal protective equipment. However, in order to provide protection, both surgical mask and N95 respirators need to be worn correctly and consistently (U.S. Food and Drug Administration [FDA] 2015). Regardless of the type of PPE, surgical masks or N95 respirators, both need to be used in combination with other public health interventions that are known to prevent disease transmission, such as engineering and administrative controls and personal hygiene practices (e.g., cough etiquette, hand hygiene, and social distancing) (Occupational Safety and Health Administration [OSHA] 2009a). If used properly and in conjunction with other controls, surgical masks and respirators both have a role in preventing different types of exposures (Occupational Safety and Health Administration [OSHA] 2009b).

Evidence suggests that some disease transmission may occur from the inhalation of microscopic airborne particles (American Industrial Hygiene Association [AIHA] 2017). Infectious diseases, particularly influenza, can be spread several ways, including:

1. Airborne droplets or sprays

2. Hand to mouth/nose/eye contact

3. Direct surface contact

4. Combinations of above listed contamination methods (American Industrial Hygiene Association [AIHA] 2017) 


\section{Surgical Masks}

Surgical masks as a physical barrier are threefold: (1) to protect the user from large droplets of blood or body fluids hazards; (2) worn to keep contaminated fingers/ hands away from the wear's mouth and nose, and (3) protect pilgrims against infection from the person wearing the surgical mask by trapping large particles of contaminated body fluids expelled by the wearer (Occupational Safety and Health Administration [OSHA] 2009a; Occupational Safety and Health Administration [OSHA] 2009b).

Surgical masks are neither designed nor certified to prevent the inhalation of small airborne viruses or bacteria (Occupational Safety and Health Administration [OSHA] 2009b). Also, because surgical masks are not designed to provide a tight seal around the wearer's face, potentially contaminated air can pass through gaps between the wearer's face and the mask during inhalation (Occupational Safety and Health Administration [OSHA] 2009b). Because the surgical mask's ability to filter small particles varies significantly based upon the type of material used in construction, they cannot be relied upon to protect against inhaling infectious organisms (Occupational Safety and Health Administration [OSHA] 2009b). In the United States, only surgical masks that are tested for their ability to resist blood and body fluids and cleared by the U.S. Food and Drug Administration (FDA) can be legally marketed in the United States (Occupational Safety and Health Administration [OSHA] 2009b; Centers for Disease Control and Prevention [CDC] 2016).

Furthermore, surgical masks are not designed to be used more than once. If a wearer's surgical mask becomes damaged or soiled, or if breathing through the mask becomes difficult, the mask should be removed, appropriately discarded, and replaced with a new mask (U.S. Food and Drug Administration [FDA] 2015). To safely discard a mask, place it in a plastic bag, and place the bag with the mask in an appropriate waste container. To help prevent any further contamination, the wearer should wash their hands with soap and water after handling the used mask (U.S. Food and Drug Administration [FDA] 2015).

\section{Disposable N95 Respirators}

Disposable N95 respirators are designed and tested to filter small air particulates; thus reducing the number of infectious particles inhaled and affording more protection than surgical masks. The "N95" designation means that when the respirator is subjected to careful testing, it blocks at least $95 \%$ of very small ( 0.3 micron) test particles (U.S. Food and Drug Administration [FDA] 2015). Respirators offer the best protection when wearers are within 6 feet/1.8 meters of others who have influenza-like symptoms (Occupational Safety and Health Administration [OSHA] 2009 b). With proper fitting to the person, the filtration capabilities of N95 respirators are greater than those of surgical masks (U.S. Food and Drug Administration [FDA] 2015). In order to provide optimal protection, respirators require a more concerted effort by the wearer in regard to use, fit, and care. Disposable N95 respirators come 
in various sizes and must be individually selected to fit the wearer's face in order to provide a tight seal and subsequent protection. A proper, tight seal between the wearer's face and respirator forces inhaled air to be pulled through the respirator's filter material and not through gaps between the wearer's face and respirator during inhalation (Occupational Safety and Health Administration [OSHA] 2009b). However, even properly fitted N95 respirators do not completely eliminate the risk for disease transmission (U.S. Food and Drug Administration [FDA] 2015). Also, since a proper fit is essential for protection, N95 respirators are not designed for children or Hajj pilgrims with facial hair. Unfortunately, a pilgrim may derive little benefit from wearing an N95 respirator that has not been properly fit-tested on the wearer. Outside of use in the occupational setting, proper fit-testing may be difficult to obtain for members of the general public (American Industrial Hygiene Association [AIHA] 2017; U.S. Food and Drug Administration [FDA] 2015).

\section{Public Use N95 Respirators}

Select filtering facepiece N95 respirators have been cleared by the FDA for use by the general public. All FDA-cleared N95 respirators are labeled as "single-use," disposable devices (U.S. Food and Drug Administration [FDA] 2015). If the respirator becomes damaged or soiled, or if breathing difficulty occurs, a person should remove the respirator, discard it properly by placing it in a plastic bag and placing both in an approved trash container, and replace it with a new one (U.S. Food and Drug Administration [FDA] 2015). Proper handwashing with soap and water after handling any respirator is required. However, in general, the CDC does not recommend facemasks and respirators for use in community settings (U.S. Food and Drug Administration [FDA] 2015). But, facemasks and respirators may be appropriate for persons at risk for severe illness from influenza or other respiratory diseases. The FDA has approved the following list of N95 respirators for use by the general public:

- $3 \mathrm{M}^{\mathrm{TM}}$ Particulate Respirator $8670 \mathrm{~F}$

- 3 M ${ }^{\mathrm{TM}}$ Particulate Respirator 8612F

- Pasture Tm F550G Respirator

- Pasture Tm A520G Respirator (U.S. Food and Drug Administration [FDA] 2015)

The proper use of surgical masks or N95 respirators is one practice, in conjunction with other environmental controls and personal hygiene practices, which may reduce the risk of infectious disease transmission. There is limited historical data (Occupational Safety and Health Administration [OSHA] 2009b) on the effectiveness of either surgical masks or N95 respirators for the control of respiratory diseases during past pandemics. The effectiveness of surgical masks and N95 respirators has been inferred based on the mode of disease transmission, (specifically influenza), particle size, and professional judgment (Occupational Safety and Health Administration [OSHA] 2009a; U.S. Food and Drug Administration [FDA] 2015). 


\title{
Controlling for Other Mass Gathering Hazards
}

\section{Other Health and Safety Hazards}

Skin chafing may be caused by long periods of standing and walking in the heat leading to fungal or bacterial skin infections (Brunette and Centers for Disease Control and Prevention [CDC] 2016). To maintain personal hygiene, clothing should be light, not restrictive, and changed often (Brunette and Centers for Disease Control and Prevention [CDC] 2016). It is recommended that pilgrims should keep skin dry, use talcum powder, and be aware of any pain or soreness caused by clothing or garments. Any sores or blisters should be disinfected and kept covered with sterile a dressing or bandage; with special attention paid to protect the feet, which are bare when inside the Grand Mosque (Brunette and Centers for Disease Control and Prevention [CDC] 2016).

When the Hajj occurs during the summer months, heat exhaustion and heatstroke are leading causes of death and disability (Brunette and Centers for Disease Control and Prevention [CDC] 2016). Pilgrims should be cognizant on minimizing the risk of heat-related injuries and illnesses, as well as sun avoidance. Particularly at dawn on the 9th day of Dhu al-Hijja, pilgrims will begin an $8.9 \mathrm{~m} / 14.4 \mathrm{~km}$ walk to the plain of Arafat (Brunette and Centers for Disease Control and Prevention [CDC] 2016). Typically, the route is supplied with cool mist sprinklers to offset the high daytime temperatures; however, the risk of heat-related illnesses increases during this part of the journey (Brunette and Centers for Disease Control and Prevention [CDC] 2016).

Pilgrims should stay hydrated with water, wear sunscreen with a minimum sunscreen protection factor (SPF) of 30, and seek shade when possible. Umbrellas may also be used to provide portable sun protection (Brunette and Centers for Disease Control and Prevention [CDC] 2016). In order to avoid oppressive daytime heat, some Hajj rituals may also be performed at night. Pilgrims can be reassured that evening rituals have been advocated as both appropriate and legitimate by religious clerics (Brunette and Centers for Disease Control and Prevention [CDC] 2016).

\section{Personal Responsibility in Abiding by General Posted Health Guidelines as Engineering, Administrative, and/or PPE Controls}

\begin{abstract}
The Ministry of Health of Saudi Arabia has published General Guide for Health of Hajj and Umrah Pilgrims (3rd edition) for all pilgrims to review and follow before partaking in the Hajj (Ministry of Health - Kingdom of Saudi Arabia. 2017b). The document's primary goal is providing Hajj and Umrah pilgrims with health education concepts to improve personal prevention practices against disease, illness, and injury. Listed are general guidelines that if administered individually and collectively, serve as effective engineering, administrative, and/or PPE controls:
\end{abstract}


1. Receiving necessary vaccinations vaccines, particularly elderly and pilgrims with chronic diseases;

2. Traveling with sufficient medications for health and/or environmental conditions.

3. Traveling with sufficient clothes appropriate for environmental conditions;

4. Traveling with sufficient detailed medical report outlining pre-existing illnesses and any prescribed medications;

5. Maintaining in good working order personal hygiene equipment, such as towels, shaving tools, soap, toothbrush and toothpaste, creams and moisturizing ointments, and an umbrella;

6. Traveling with sufficient supply of essential disinfectants, hand sanitizers, antipyretics, and painkillers;

7. For diabetics, traveling with and maintaining in good working order a reliable and accurate glucose meter;

8. Walking or standing for short periods after remaining stationary for long periods of time (1-2 $\mathrm{h}$ in length).

9. Acquiring a medical checkup before traveling to help ensure a successful Hajj pilgrimage (Ministry of Health - Kingdom of Saudi Arabia. 2017b).

\section{Public Health Education and the Hajj}

Implementation of administrative, PPE, or personal hygiene hazard controls, in part or in whole, will only be effective if properly communicated and followed. Those hazards, as identified through public health surveillance and monitoring, require proper health education dissemination to pilgrims. Proper health education communication should take into consideration an appreciation of the diverse characteristics of all Hajj travelers. Providing health education to travelers through various modes of has been shown to improve short-term health knowledge which may promote positive health behaviors (Turkestani et al. 2013). Even with an increase in short or long-term health knowledge, proper behavior modification occurs when a person believes that he or she is susceptible to a hazard or considers a hazard serious to their health. As well, establishing a personal sense of selfefficacy, empowering an individual to take control of his/her own health and health outcomes, will ultimately decide the fate of any health education programming. However, for health education to be effective, special consideration must be given to modes of communication and the cultural appropriateness of that communication (Nishtar et al. 2004; Saha et al. 2005). Those communication barriers (e.g., environmental and cultural) and modes of communication (e.g., social media messages, lectures, public addresses, posters, and leaflets); as well as group characteristics (e. g., age, gender, and background) need to be factored into the health education message (Abolfotouh 1995; Werner and Wilson 1981). Major limitations to implementing health education to Hajj pilgrims are similar to health promotion programming in other settings. Restricted time and available resources to conduct proper and repeated health promotion programming presents significant limitations (Shirah et al. 2017). 


\section{Kingdom of Saudi Arabia Ministry of Health (MOH)}

Established in 1950, the Kingdom of Saudi Arabia Ministry of Health's (MOH) primary responsibility is delivering integrated and comprehensive healthcare services for the citizens of Saudi Arabia; as well as Hajj travelers irrespective of region or country (Saudi Ministry of Health 2018a). Since inception, top MOH priorities have focused on inclusive public health and disease control measures. These specific policies and projects focus on providing both general and specific health services to address health conditions; specifically non-communicable diseases, nutrition, reproductive health, smoking (tobacco-use), AIDS, traffic accidents, and injuries. (Saudi Ministry of Health 2018a). Capacity-building collaboration and cooperation with international organizations helped establish an infrastructure for comprehensive health services, including care for Hajj and Umrah pilgrims.

The Kingdom of Saudi Arabia Ministry of Health (MOH) publishes health requirements and regulations for the care of all pilgrims before each Hajj season. Pilgrims in their countries or origin should consult with their respective health authorities prior to travel regarding pre-event, event, and post-event personal health measures to prevent illness and injury. To be effective, public health information and campaigns should be provided so as to be interpreted appropriately and with cultural competency.

Finally, effective cooperation and communication between agencies, both within and outside the Kingdom of Saudi Arabia, is paramount in the health promotion and disease surveillance of pilgrims. Health, environmental, transportation, and border security are some examples in which effective agency collaboration and communication can together mitigate hazards and promote traveler health (Shafi et al. 2016).

The Kingdom of Saudi Arabia Ministry of Health established health guidelines, disseminated electronically through the $\mathrm{MOH}$ portal, specific to the health education of Hajj pilgrims (Saudi Ministry of Health 2018b). Public health guidelines for current Hajj pilgrims (Hajj 1439 H.) have been established for travelers addressing: (1) During Hajj, (2) Chronic Diseases, (3) Woman and Child, and (4) After Hajj (Saudi Ministry of Health 2018a). A more robust description of health guidelines for each of these four areas may be accessed through the $\mathrm{MOH}$ portal (www.moh.gov.sa/en/Hajj/HealthGuidelines/Pages/default.aspx).

In general, each pilgrim should ensure proper maintenance of pertinent vaccinations prior to travel; as well as awareness of disease transmission and disease symptoms; with special consideration given to the education of respiratory diseases. Advice on standard personal hygiene measures and general food and drink hygiene practices, to minimize food and waterborne diseases and gastrointestinal illness should be provided. Special public health education consideration should be given to those with preexisting conditions, older pilgrims, and first-time travelers. 


\section{During Hajj MOH Health Education Guidelines}

During Hajj, health guidelines have been established for protection against infectious and communicable diseases, with a focus on five practice areas: (1) General Hygiene and Cleanliness; (2) Shaving and Haircutting; (3) Food Poisoning Protection; (4) Heat Exhaustion and Sun Stroke Protection; and (5) Guidelines for Patients with Chronic Diseases.

Established hygiene and cleanliness health recommendations for bathing, handwashing, cleanliness of person and personal surroundings, and proper facemask donning and doffing hygiene practices are emphasized. Particular infection control emphasis is given to coughing and sneezing etiquette, including the use of handkerchiefs as a barrier, with proper trash disposal soon after use. In the event where no handkerchief is available, sneezing or coughing into the upper arm as a barrier method is recommended. Facemask use, particularly in crowded areas, is recommended as an additional barrier method. As mentioned, an integral component of facemask effectiveness is being mindful of routine facemask changing on a 6-h basis, when dirty, or in accordance to manufacturer guidelines. Facemask recommendations are expanding to include those population dense event areas (i.e., during circumambulation of the Ka'ba (Tawaf), stoning (Rajm), and walking between Safa and Marwa (Sa'i)) (Saudi Ministry of Health 2018a).

Shaving and haircutting health education hygiene practices established by $\mathrm{MOH}$ stress individual self-care to protect against infectious diseases such as hepatitis (B), hepatitis (C), and HIV/AIDS (Saudi Ministry of Health 2018a). It is recommended that once-use shavers be utilized and to never share personal razors (or other personal items), such as brushes, with other travelers. As well, if a pilgrim chooses to use a barber, to be attentive of selecting a reputable barber and to resist the services of street barbers during the course of the event (Saudi Ministry of Health 2018a).

Food poisoning protection guidelines established by $\mathrm{MOH}$ parallel general personal hygiene practices. In addition to the washing of hands with soap and water before and after food preparation, guidelines for food selection, storing, and cooking are outlined. Food selection should be performed with expiry dates in mind. Food storage should be such as to keep foodstuffs out of the elements, away from insects, and at proper temperature. It is recommended that cooked food is stored for no more than $2 \mathrm{~h}$ at room/bus temperature, in order to deter from bacteria growth and food poisoning (Saudi Ministry of Health 2018a).

Hazards from exposure to environmental elements, particularly prolonged exposure to sun and heat, cannot be overstressed. The Kingdom of Saudi Arabia Ministry of Health public health guidelines for the prevention of heat exhaustion and sunstroke promote the adequate consumption of liquids, use of umbrellas, the wearing of loose, light colored clothing, and the proper incorporation work (walk)/ rest periods. Avoidance measures include reducing prolonged sun exposure and physical exertion for extended periods of time (Saudi Ministry of Health 2018a). Noted areas and times of frequent heat injuries have been identified. The Saudi Ministry of Health ( 2018a) identifies the Tawaf (circumambulation of the Ka'ba), at midday, Sa'i (walking between Safa and Marwa), during crowding and at high 
temperatures, Arafat at midday, and Mina (places of slaughtering the sacrificial animals and stoning), due to long travel distance and congestion as areas of increased risk for heat exhaustion and sunstroke.

Finally, The Saudi Ministry of Health (2018a) outlines health guidelines specific to the signs and symptoms of heat exhaustion or sunstroke. Pilgrims should be aware of high body temperature, as well as other traditional signs and symptoms of heat exhaustion or sun stroke, such as headache, dizziness, nausea, fatigue, thirst, and/or cramping of the abdominal and leg muscles. To combat heat related illness and injury, guidelines established include (1) resting in shady areas; (2) cooling the body with cold water; (3) acquiring adequate sleep; (4) when necessary, administration of antipyretics and painkillers; and (5) in severe cases, admission to the nearest health center for further treatment.

Public health education guidelines during the Hajj for patients with chronic diseases focus on proper preparation before travel and communication at the event. Before Hajj, physician consultation to assess current health status is recommended. Before travel, any prescribed medications should be inventoried, packed, and properly stored. At Hajj, pilgrims on a medication regimen should adhere to physician instruction and take medicines at the prescribed times (Saudi Ministry of Health 2018a). As well, travels should communicate disease-specific details while at Hajj to others in attendance. It is recommended to adhere to the person an information card, outlining: name, age, disease, the kind of treatment, address and contact information. Communication with fellow pilgrims regarding disease condition and the use of Hajj legal concessions when warranted (e.g., assigning someone to do the stoning ritual on your behalf) are recommended (Saudi Ministry of Health 2018a) aids in securing a productive and successful Hajj pilgrimage.

\section{Pilgrims with Chronic Disease Conditions MOH Health Education Guidelines}

During Hajj, the Saudi Ministry of Health ( 2018a) have designated health guidelines through their electronic portal for five chronic disease areas: (1) Heart and Hypertension, (2) Diabetes, (3) Asthma, (4) Kidney/Renal, and (5) Epilepsy/ Seizures. Due to the complex etiology of each chronic condition, it is paramount that each pilgrim, diagnosed with these specific chronic disease conditions or other illnesses, first consult with their physician prior to any travel. Health education guidelines are similar to those during Hajj recommendations. Physician evaluation, inventory, storage, and transportation of medications, timely medication administration, sign and symptom awareness, and health communication with other travelers and Hajj health authorities is recommended. As before, a more detailed description of health guidelines for these five specific chronic disease condition may be accessed through the MOH portal (www.moh.gov.sa/en/Hajj/HealthGuidelines/Pages/default. aspx). One other common theme in properly managing these listed condition, or 
others, is to seek assistance from nearest health center or hospital. Health centers and stations are strategically positioned at Hajj and noted event areas for rapid response and treatment of these and other health conditions (Saudi Ministry of Health 2018a).

\section{Women and Children Pilgrims MOH Health Education Guidelines}

Guidelines for the health of women and children have also been taken into account with specific notation regarding the physical effort required for the journey (Saudi Ministry of Health 2018a). With reference to maternal (women's) health, recommendations are outlined addressing health during menstruation and pregnancy. The Saudi Ministry of Health ( 2018a) recommends that women pilgrims consult their obstetrician-gynecologist physician before travel in order to properly perform Hajj rites. If pregnant, the $\mathrm{MOH}$ recommends postponement of the Hajj for specific reasons and cases.

Specific reasons for pregnant women to postpone the Hajj include risk of:

1. Unexpected pregnancy complications;

2. Sun stroke;

3. Physical overexertion;

4. Physical injury from overcrowded conditions;

5. Dehydration or insufficient hydration (Saudi Ministry of Health 2018a).

Specific cases for pregnant women to postpone the Hajj include history of:

1. Preterm births;

2. Early miscarriage cases;

3. Diabetes during pregnancy;

4. Pilgrims with diagnoses heart, hypertension, or kidney disease (Saudi Ministry of Health 2018a).

In the case of proper pre-travel medical clearance to attend Hajj, pregnant women should be made aware of the following Saudi Ministry of Health (2018a) health published guidelines:

1. Obstetrician-gynecologist physician consultation to minimize any health complications from attending the Hajj.

2. Possible vaccination against meningitis and influenza at least 10 days before the Hajj.

3. Inventory of all the necessary medicines.

4. Fitting and use of proper clothing and footwear.

5. Adequate fluid supply for entire Hajj attendance.

6. Walking for an hour to $2 \mathrm{~h}$, to reduce the risk of leg deep vein thrombosis.

7. Avoid overcrowded areas and choose times of less crowding to perform Hajj rites. 
8. Utilize the nearest health center, station, or hospital in the event of bleeding, abdominal contractions, and migraine, or when high temperature occurs.

9. Avoid any excessive physical effort and to apply legal Hajj concessions and license according to conditions when necessary such as the use of a wheelchair during Tawaf (circumambulation) and Sa'i (walking) (Saudi Ministry of Health 2018a).

The Saudi Ministry of Health ( 2018a) recommends against prepubescent children attending the Hajj for several reasons. Recommendations for prepubescent children abstaining from the Hajj include the increased risk of:

1. Respiratory and digestive tract infections;

2. Fluid loss;

3. Physical exhaustion;

4. Getting loss in areas of overcrowding (Saudi Ministry of Health 2018a).

In cases in which children and in the accompaniment of mothers attending the Hajj, the Saudi Ministry of Health ( 2018a) stresses adherence of children to all general health guidelines for attendance. Other children-specific guidelines include:

1. Wearing identification with full name, place of residence, contact telephone number, and convoy name and contact information.

2. Current and up-to-date vaccination schedule and Hajj-related vaccinations.

3. Administration of Escherichia coli bacterium (Haemophilus influenza) 10 days before travel (if not already part of their vaccination schedule or Hajj-related vaccinations).

4. Maintaining adequate fluid intake.

5. Educated in proper handwashing practices.

6. Maintaining proper skin care practices to prevent drying and chafing.

7. Educated in proper food hygiene practices.

8. Avoidance of overcrowded areas as much as possible.

9. Utilize the nearest health center, station, or hospital if and when any health problems occur such as diarrhea, vomiting, or high body temperature (Saudi Ministry of Health 2018a).

\section{After Hajj MOH Health Education Guidelines}

After Hajj health guidelines have been instituted by the Kingdom of Saudi Arabia Ministry of Health (Saudi Ministry of Health 2018a) to address signs and symptoms experienced post-Hajj. Commonly reported post-Hajj health concerns include muscle strain and pain, headaches, cold symptoms, lethargy, irregular sleep patterns, and skin complexion darkening. Common contributors to the listed health conditions include physical exertion with or in the absence of proper physical 
conditioning, excessive sun exposure, and coming in contact with pilgrims infected with the cold and/or influenza virus.

After returning, the following post-Hajj health advice is recommended:

1. Adequate rest.

2. Proper fluid consumption.

3. Analgesic medications if needed and prescribed.

4. Those with preexisting chronic conditions exacerbated from Hajj travels should see their physician for proper medical guidance (Saudi Ministry of Health 2018a).

The importance of proper physical fitness, along with maintaining an ideal weight, is stressed, particularly in promoting a successful and healthy future Hajj pilgrimage (Saudi Ministry of Health 2018a). The best time to prepare for the subsequent Hajj pilgrimages is on return from present travels.

\section{Conclusion}

In order to promote a successful and healthy Hajj, pilgrims should prepare in advance to anticipate and recognize common health or environmental hazards that may be encountered during their journey. To this end, the Kingdom of Saudi Arabia Ministry of Health established health guidelines, disseminated electronically through the $\mathrm{MOH}$ portal, specific to the health education of Hajj pilgrims addressing: (1) during Hajj, (2) chronic diseases, (3) woman and child, and (4) after Hajj traditionally; established hazard control measures include: (1) elimination, (2) substitution, (3) engineering controls, (4) administrative controls, and (5) personal protective equipment (PPE), with maintaining a current immunization schedule as an important engineering control. As well, on an individual level, attention to regimented personal hygiene practices is shown to be an effective public health administrative control measure. Preparation for a healthy pilgrimage should begin in earnest, with preparation for the subsequent Hajj pilgrimages after returning from recent Hajj travels.

\section{References}

Abolfotouh MA (1995) The impact of a lecture on AIDS on knowledge, attitudes and beliefs of male school-age adolescents in the Asir Region of southwestern Saudi Arabia. J Community Health 20(3):271-281

American Chemical Society [ACS] (2015) Control measures. Retrieved from https://www.acs.org/ content/acs/en/about/governance/committees/chemicalsafety/hazard-assessment/fundamentals/ control-measures.html

American Industrial Hygiene Association [AIHA] (2017) AIHA fact sheet: respiratory protection for reducing disease transmission: information for the general public. Retrieved from https://www.aiha.org/about-ih/Documents/RespiratorFactSheet-GenPub.pdf

Brunette GW, Centers for Disease Control and Prevention [CDC] (2016) CDC health information for international travel 2016: the yellow book. Oxford University Press, New York 
Centers for Disease Control and Prevention [CDC] (2009) Planning for 2009 H1N1 influenza:

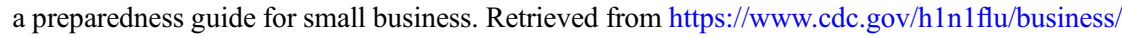
guidance/smallbiz.htm

Centers for Disease Control and Prevention [CDC] (2012) Severe Acute Respiratory Syndrome (SARS): SARS basics fact sheet. Retrieved from https://www.cdc.gov/sars/about/fs-sars.html

Centers for Disease Control and Prevention [CDC] (2015) The National Institute for Occupational Safety and Health (NIOSH): hierarchy of controls. Retrieved from https://www.cdc.gov/niosh/ topics/hierarchy/

Centers for Disease Control and Prevention [CDC] (2016) The National Institute for Occupational Safety and Health (NIOSH): personal protective equipment. Retrieved from https://www.cdc. gov/niosh/ppe/

Centers for Disease Control and Prevention [CDC] (2017) National Center for Emerging and Zoonotic Infectious Diseases (NCEZID). Retrieved from https://www.cdc.gov/ncezid/

Eltahir AHH (2000) Development of health services in hajj seasons. J Fam Community Med $7(1): 13-14$

Masood K, Gazzazz J, Ismail K, Dhafark O, Kamal A (2007) Pattern of psychiatry morbidity during Hajj at Al-Noor Specialist Hospital. Int J Psychiatry Med 37(2):163-172

Meysamie A, Ziaee-Ardakani H, Razavi SM, Doroodi T (2006) Comparison of mortality and morbidity rates among Iranian pilgrims in Hajj 2004 and 2005. Saudi Med J 27(7):447-451

Ministry of Health - Kingdom of Saudi Arabia (2017a) Hajj 1437, Health regulations. Retrieved from http://www.moh.gov.sa/en/hajj/pages/healthregulations.aspx

Ministry of Health - Kingdom of Saudi Arabia (2017b) General guide for health of Hajj and Umrah pilgrims. 1438H (2017G) (3rd edn). Retrieved from https://www.moh.gov.sa/Hajj/Documents/ Languages/ENGLISH.pdf

Ministry of Health - Kingdom of Saudi Arabia (2018a) Media center. Retrieved from https://www. moh.gov.sa/en/Pages/Default.aspx

Ministry of Health - Kingdom of Saudi Arabia (2018b) Hajj 1439, Health guidelines. Retrieved from https://www.moh.gov.sa/en/Hajj/HealthGuidelines/Pages/default.aspx

New York Committee for Occupational Safety \& Health (n.d.) Hierarchy of hazard controls. Retrieved from http://nycosh.org/wp-content/uploads/2014/10/Hierarchy-of-Hazard-ControlsNYCOSH.pdf

Nishtar S, Zoka N, Nishtar SS, Khan SY, Jehan S, Mirza YA (2004) Posters as a tool for disseminating health related information in a developing country: a pilot experience. J Pak Med Assoc 54(9):456-460

Occupational Safety and Health Administration [OSHA] (2009a) Guidance on preparing workplaces for an influenza pandemic. OSHA 3327-05R. Retrieved from https://www.osha. gov/Publications/influenza_pandemic.html

Occupational Safety and Health Administration [OSHA] (2009b) OSHA fact sheet: respiratory infection control: respirators versus surgical masks. Retrieved from https://www.osha.gov/ Publications/respirators-vs-surgicalmasks-factsheet.pdf

Occupational Safety and Health Administration [OSHA] (2016) General requirements. OSHA 1910.132. Retrieved from https://www.osha.gov/pls/oshaweb/owadisp.show_document?p_ $\mathrm{id}=9777 \& \mathrm{p}$ table $=$ STANDARDS

Saha A, Poddar E, Mankad M (2005) Effectiveness of different methods of health education: a comparative assessment in a scientific conference. BMC Public Health 5:88. https://doi.org/ $10.1186 / 1471-2458-5-88$

Saudi Ministry of Health (2016) AHMED travel 2016. Retrieved from http://www.ahmed-travel. $\mathrm{com} /$ hajj-packages/2-uncategorised/101-saudi-ministry-of-health-requirements-and-health-mat ters.html

Shafi S, Dar O, Khan M, Khan M, Azhar EI, Mccloskey B, Zumla A, Petersen E (2016) The annual Hajj pilgrimage-minimizing the risk of ill health in pilgrims from Europe and opportunity for driving the best prevention and health promotion guidelines. Int J Infect Dis 47:79-82. https://doi.org/10.1016/j.ijid.2016.06.013 
Shirah BH, Zafar SH, Alferaidi OA, Sabir AM (2017) Mass gathering medicine (Hajj Pilgrimage in Saudi Arabia): the clinical pattern of pneumonia among pilgrims during Hajj. J Infect Public Health 10(3):277-286. https://doi.org/10.1016/j.jiph.2016.04.016

The Council of British Hajjis [CBHUK] (2010) Health tips - NATHNAC: advice for pilgrims for the Hajj and Umrah. Retrieved from http://dobuy.co.uk/cbhuk/?page id=256

Turkestani A, Balahmar M, Ibrahem A, Moqbel E, Memish ZA (2013) Using health educators to improve knowledge of healthy behaviour among Hajj 1432 (2011) pilgrims. East Mediterr Health J 19(Suppl 2):9-12. https://doi.org/10.26719/2013.19

U.S. Food and Drug Administration [FDA] (2015) Masks and N95 respirators. Retrieved from https://www.fda.gov/MedicalDevices/ProductsandMedicalProcedures/GeneralHospitalDevice sandSupplies/PersonalProtectiveEquipment/ucm055977.htm

Vanderbilt Heath (2017) Vanderbilt health travel clinic. Retrieved from https://www. vanderbilthealth.com/travelclinic/20777

Werner RT, Wilson JM (1981) Are health education conferences effective? An evaluation of knowledge gain in a three-day institute. Health Educ 12(4):22-24

World Health Organization [WHO] (2016) The Weekly Epidemiological Record (WER), World Health Organization. Retrieved at March 8, 2016, from the website temoa Open Educational Resources (OER) Portal at http://www.who.int/wer/2016/wer9126-27.pdf?ua=1 